\title{
Das Ende einer Dynastie
}

\section{Erhard Taverna}

Dr. med., Mitglied der Redaktion

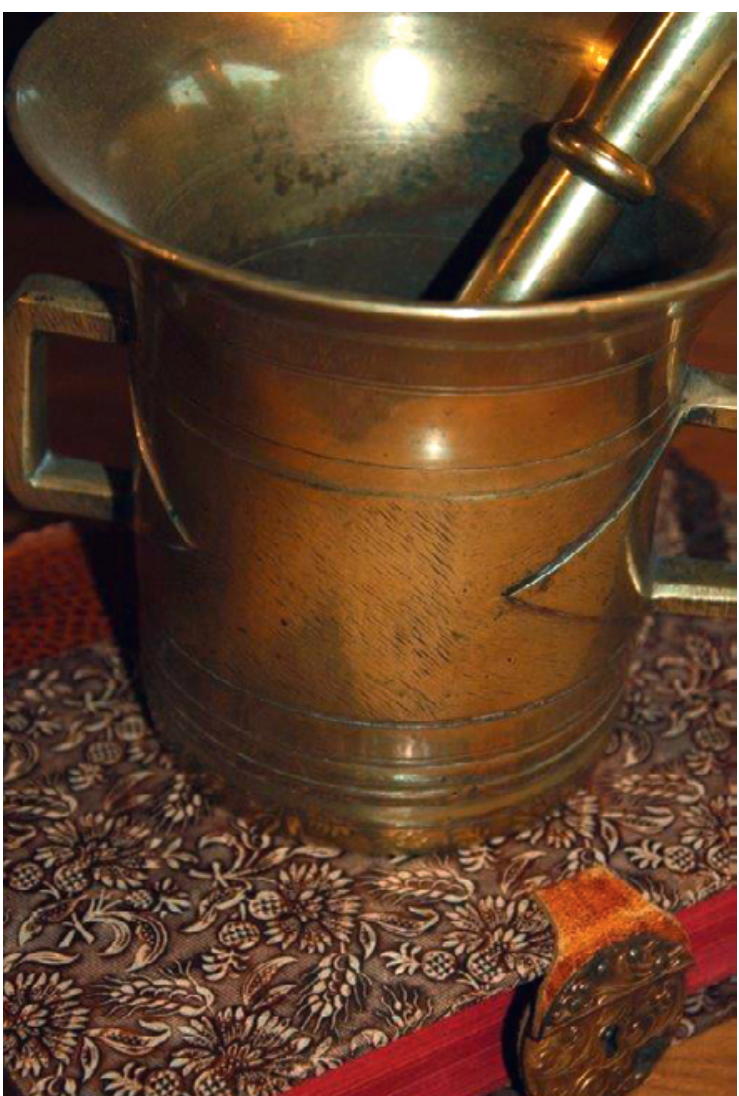

Das Haus am Dorfrand war von der Strasse nur über einen Fussweg zu erreichen. Ein typisches Weberhöckli, ohne Stall, mit bodennahen Fenstern, wo einst gewebt wurde. Die Eschen und Buchen vom nahen Bach wuchsen bis an die brettgetäfelte Fassade. Die rissig-grauen Rundschindeln an der Wetterseite waren beschädigt und hätten schon lange ersetzt werden müssen. Brennholzbeigen flankierten den Eingang, mit denen im Winter der einzige Ofen zwischen Küche und Wohnzimmer Tag und Nacht beheizt wurde.

Die Grossmutter war eine bekannte Hellseherin und Naturärztin gewesen, die Vieh und Menschen half.

Der einzige Sohn, ein betagter, wortkarger Junggeselle, bewohnte mit seiner pflegebedürftigen Mutter das baufällige Haus. Die Grossmutter war eine über die Kantonsgrenzen hinaus bekannte Hellseherin und Naturärztin gewesen, die Vieh und Menschen half. Volle Buchregale im Webkeller zeugten auch nach ihrem Tod von ihren breiten Interessen, die neben der Imkerei Kräuterbücher, Gesundheitsratgeber, Astrologiekalender und Esoterikliteratur umfassten. Neben ihrer Plattstichweberei fand sie Zeit, telepathisch beim Auffinden verlorener Gegenstände mitzuwirken, Salben herzustellen und eigene Rezepturen zu entwickeln. Die Tochter hatte vieles von der mütterlichen Tradition übernommen, wobei die moderne Zeit ihr entgegenkam, indem sie ihre hellsichtigen und geistheilenden Botschaften telefonisch verstärkt verbreitete. Wer mit einer Grossportion Urin aus Zürich herreiste oder das Kleidungsstück eines reiseunfähigen Familienmitgliedes mitbrachte, nahm auf einer abgewetzten Couch im Wohnzimmer Platz. Während sie in der Küche hantierte, gab es hier genug zu sehen, um sich die Wartezeit zu verkürzen. Stapelweise lagen Bücher auf Fenstersimsen. Mit Spiritus gefüllte Einmachgläser, in denen Kröten, Eidechsen und undefinierbares Getier in allen Zerfallsstadien verbleichten, standen auf einer Kommode. Wild geformtes Wurzelwerk und getrocknete Kräuterbündel hingen an Schnüren von der Decke herab. Auch gab es da aufgerissene Kartons voller Medizinfläschchen und Korkpfropfen, in die sie ihre Mixturen abfüllte. Viele Gerätschaften wie Mörser, Waagen und ein unvollständiger Destillierapparat wa-

Wenn ihm der Rummel zu viel wurde, verschwand er wortlos hinter dem Haus oder ging zum nahen Bach.

ren verstaubt und blieben ungebraucht, nur noch als Blickfang nützlich. Die Herstellung von Salben hatte sie altershalber aufgegeben, zu mühsam war das Aufkochen von Dachsenschmalz, das Erhitzen von Öl und Wachs, das Filtrieren der Kamillen- und Ringelblumenextrakte. Ihr Sohn, ein frühzeitig gealterter Rentner, ging ihr zur Hand, so gut er es konnte. Ihm fehlte das Geschick seiner weiblichen Vorfahren. Lieber sammelte er die gewünschten Kräuter und Pilze, schoss ein paar Krähen, Füchse oder Dachse, als dass er sich um die zahlreichen Klienten kümmerte, die immer noch 
auf der Suche nach einem Parkplatz umherirrten, bevor sie mit ihren vielseitigen Anliegen über den schmalen Wiesenweg stapften. Wenn ihm der Rummel zu viel wurde, verschwand er wortlos hinter dem Haus oder ging zum nahen Bach, hackte Holz und büschelte Äste zu brennbaren Bündeln. Seine mangelnde Begabung machte ihn zu ihrem Sorgenkind. Sie tat sich schwer damit, dass er weder ein Heiler noch ein Hellseher war. Dass er stundenlang am Stubentisch sass und zeichnete, zählte nicht. Frei-

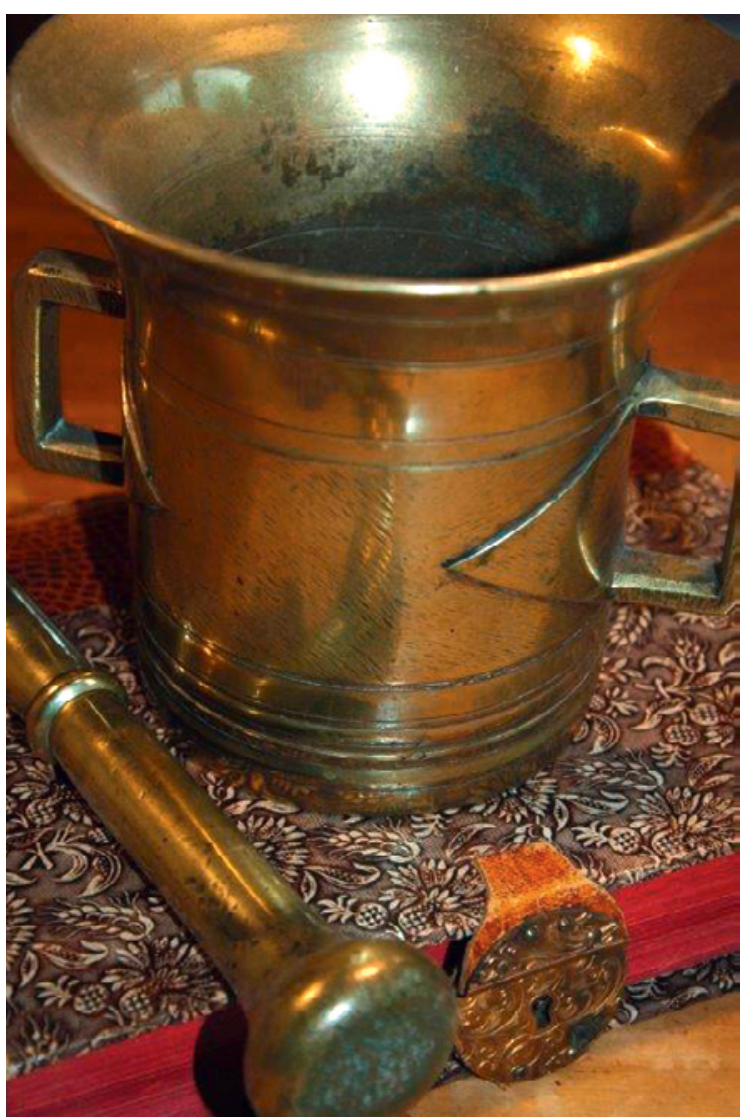

händig mit Bleistift auf Papier und Karton entwarf er Maschinen mit Zahnrädern und Kolben, komplizierte,

\section{Das Haus steht noch. Ein Parkplatz grenzt an das schicke Feriendomizil.}

uhrenähnliche Apparaturen mit hingekritzelten, unleserlichen Gebrauchsanweisungen. Für seine Entwürfe und Tabellen benützte er die Astrologiebücher der Grossmutter, deren Abbildungen er zu einer geheimnisvollen Mechanik erweiterte, allerdings ohne das Gezeichnete jemals als Modell zu realisieren. Es blieb bei den zusammengerollten Konstruktionsplänen, die er in seinem Zimmer in einen Schrank einschloss.

Dann starb die Mutter. Er verstummte noch mehr, gab bald auch das Zeichnen auf, lebte von seiner kleinen Rente und wurde nur selten im Dorf gesehen. Die Vormundschaftsbehörde wählte einen Beistand, der ihm im nahen Pflegeheim einen Platz fand, den der Erlös vom Hausverkauf finanzierte.

Dort blieb er der Eigenbrötler, der er schon immer war, wenngleich ihm das regelmässige, warme Essen zu behagen schien. In guten Tagen malte er verschlungene Kreise und Rechtecke auf den Rand alter Zeitungen, doch wenn immer möglich vermied er jede Gesellschaft und verkroch sich mit seiner erkalteten Pfeife in die dunkelsten Winkel des Hauses. Das wurde ihm schliesslich zum Verhängnis, denn einer dieser schlecht einsehbaren und kaum beleuchteten Winkel befand sich am unteren Ende des Treppenlifts. Dort starb er durch einen Genickbruch, als die Plattform des neu installierten Liftes mit voller Wucht dem Sitzenden in den Rücken fuhr. Das Haus steht noch. Inventar und Papierrollen landeten in einer Mulde. Ein Parkplatz grenzt an das schicke Feriendomizil.

Bildnachweis

Fotos: Erhard Taverna 